\title{
Increasing the technical level of mining haul trucks
}

\author{
Yuri Voronov ${ }^{1}$, Artyom Voronov $^{1}$, Sergey Grishin ${ }^{1}$, and Alexey Bujankin ${ }^{1}$ \\ ${ }^{1}$ T.F. Gorbachev Kuzbass State Technical University, Kemerovo, Russian Federation
}

\begin{abstract}
Theoretical and methodological fundamentals of mining haul trucks optimal design are articulated. Methods based on the systems approach to integrated assessment of truck technical level and methods for optimization of truck parameters depending on performance standards are provided. The results of using these methods are given. The developed method allows not only assessing the truck technical levels but also choosing the most promising models and providing quantitative evaluations of the decisions to be made at the design stage. These areas are closely connected with the problem of improvement in the industrial output quality, which, being a part of the widely spread in Western world "total quality control" ideology, is one of the major issues for the Russian economy.
\end{abstract}

\section{Introduction}

Technical re-equipment of open-pit mining facilities and further development and upgrades of automotive mining machinery are inextricably linked. Efficiency in execution of hauling operations determines the technical and economic performance indicators of coal production on the whole, as transportation costs make up more than $50 \%$ of overall mining costs.

So far skyrocketing payload capacity as the main tendency for mining automotive machinery development has not been accompanied by a corresponding gain in performance and increase in other merits. However, it should be noted that the engineering policy meant to increase the payload and aimed at further mining truck redesign without major quality changes. Open-pit mining transport enhancement can be achieved, in the first place, by optimal tuning of all the structural components, units and systems of a truck not only among themselves, but with the facility environment as well. So when designed, a mining haul truck must be regarded as a complex technical aggregate being in its turn a part of the total surface mining transport system.

Vast amounts of mined bulk to be transported by haul trucks, influence of hauling operations upon the speed of open-pit mining and their high labour intensity stimulate the constant search for large-scale improvements to the mining transport. M.V. Vassiliev, A.A. Kuleshov, M.G. Potapov, K.N. Trubetskoy, S. Alarie, M. Gamache, C.N. Burt, L. Caccetta, R.A. Carter, V.A. Temeng and others contributed greatly to the theory and practice of automotive mining machinery usage at open-pit facilities. In their papers they determined the sphere of haul truck efficient use in open-pit mining [1, 3, 5, 8-10], summed up the experience of its operation [2, 4, 7, 11-14], highlighted the issues of techno-economic studies devoted to automotive mining machinery usage efficiency [1-7, 15-17]. 
Belarusian Automobile Plant (OJSC "BelAZ", Republic of Belarus) is a major world manufacturer of heavy dump trucks used in mining and construction. Its production mainly consists of mining dump trucks with a payload capacity of 30 to $360 \mathrm{t}$. During all the years (since 1948 when the company was founded) "BelAZ" specialists have been doing their best to enhance the truck design. These design implementations contributed to providing mining companies with high-performance equipment. However in recent years "BelAZ" designing engineers have had to face the following problem: increased payload did not lead to the proportional rise in truck performance. The power-to-weight ratio is still insufficient, the payload ratio and life mileage are too low as well as the truck technical level in general and only production and maintenance costs go up with every passing year.

This situation can be due to the fact that the theory of mining machinery optimal design (including mining dump trucks) has not been developed sufficiently yet. Mining truck design framework still needs the procedures for ultimate solutions' synthesis.

\section{Results and discussion}

In order to estimate adequately the technical level and quality of the mining machinery (including automotive machinery) the most agreeable alternative is the expert assessment method, which allows assessing functionally homogeneous machines of various types, models and modifications. It was proposed by G. Solod. For this purpose by the technical level the truck quality at the stage of the design development is meant.

Another important issue of the assessment is the grounded selection of the parameters determining the technical level of haul trucks to have the essential and sufficient nomenclature. The parameters that determine the technical level to the most are selected from the initial nomenclature after a thorough analysis of the operational processes followed by a further verification of their matching (direct correlation) and representativity (the degree of influence upon the technical level depending, in its turn, on the purpose of its assessment). Eventually the following system of the parameters was obtained (Fig. 1).

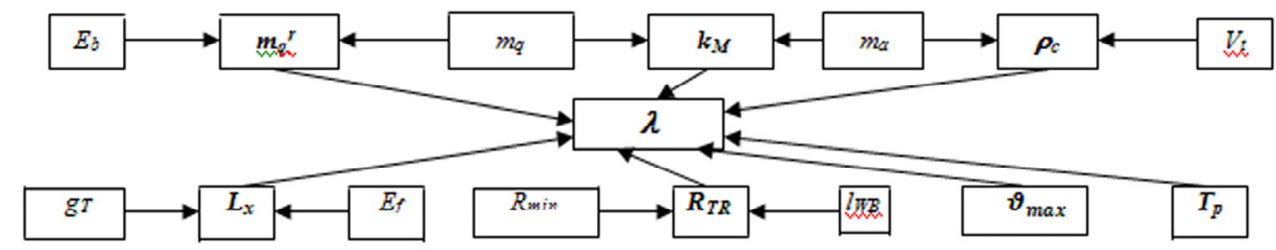

Fig. 1. Complex of haul trucks technical level parameters.

In this system: $\lambda$ - functional criterion, $\mathrm{kW} / \mathrm{t} ; m_{q}^{r}=m_{q} / E_{b}$ - truck specific payload, $\mathrm{t} / \mathrm{m}^{3}$; $k_{M}=M / m_{w}$ - truck weight coefficient (comparative materials consumption); $\rho_{c}=m_{a} / V_{t}$ - component density, $\mathrm{t} / \mathrm{m}^{3} ; L_{x}=100 E_{f} / g_{T}$-distance to empty, $\mathrm{km} ; \quad R_{T R}=R_{\min } / l_{W B}-$ specific turn radius; $\vartheta_{\text {max }}$ - maximum speed of the truck, $\mathrm{km} / \mathrm{h} ; T_{p}$ - predetermined service life (truck mileage), km; $m_{q}$ - truck payload capacity, t; $E_{b}$ - body capacity, $\mathrm{m}^{3} ; m_{a}$ - empty truck weight, $\mathrm{t} ; V_{t}$ - total truck volume (product of length by width and height), $\mathrm{m}^{3} ; E_{f}-$ fuel tanks capacity, $1 ; g_{T}$ - linear fuel consumption, $1 / 100 \mathrm{~km} ; R_{\min }-$ minimum turn radius, m; $l_{W B}$ - truck wheelbase, $\mathrm{m} ; M=m_{a}+m_{q}$ - gross truck weight, t; $m_{w}=\left(0,212 N_{e}-8,4\right)-$ truck weighted average mass (corresponding to the installed engine capacity $N_{e}$ ).

The given parameters can be determined at the earliest stages of truck design. The integrated assessment of the technical level is carried out by means of unique $\left(q_{i j}\right)$ and generalized $\left(k_{i}\right)$ parameters according to the formulae of the Solod's method. 
In the paper according to the selected parameters a comparative assessment of 22 trucks was made, 14 of which are "BelAZ" products, 4 - of "Caterpillar", 1 of "Komatsu" and 1 of "Unit Rig". This group comprises the whole range of truck payload capacities (30 to $320 \mathrm{t}$ ). The trucks are compared in similar conditions.

After the generalized parameter of the truck technical level was calculated and analyzed it can be concluded that for all 22 trucks this parameter exceeds 0,5 (Fig. 2), therefore, this result proves that the technical level of all the trucks is quite high.

The average technical level for all the machines is 0,695 . Also it should be noted that the level of "BelAZ" trucks and that of the trucks produced by foreign companies are virtually the same. The average value of the technical level generalized parameter for the trucks considered is 0,698 and that is only $0,7 \%$ higher than for "BelAZ" trucks, which means that as far as the vehicle structure perfection and new design ideas and solutions concerned Belarusian Plant products show very little difference.

On the basis of the analysis it can be concluded that power-to-weight ratio of new vehicles is to be increased, empty weight is to be lowered while reliability and service period are to be raised to a higher level; all truck parameters are to be balanced and reviewed as interrelated and interdependent. All this shows that the system approach to new wheeled open-pit mining machinery design is essential.

At the present moment there is a distinctive deficiency of guidance materials and norms and specifications that could standardize products optimal design as an important stage of quality improvement. System approach is to be regarded fundamental for optimal design as it allows perceiving the vehicle as a whole while its individual elements are being designed. The system approach to the vehicle parameters' determination consists of the following: 1) every parameter must correlate optimally with the others; 2 ) output operational performance established on the basis of these parameters is to comply with the specified values. It is suggested that the mathematical model of truck parameters optimization should be presented as a set of regression analysis equations directly connecting output operational performance and the parameters which are to be optimized.

Haul truck as a system is characterized by its own structure and parameters. The truck structure predetermines its elements and their interrelationships; it is to ensure the truck optimal functioning and for this purpose the parameters characterizing the truck are to be optimized. It is reasonable to use generalized evaluations of the technical level as optimization criteria and its unique indicators as optimized parameters. Such approach enables to reduce the problem dimensions, to simplify its solution and also to ensure objective assessments of the suggested solutions.

After carrying out the analysis of the output operational performance (such as payload ratio $k_{T}$ and $90 \%$ predetermined service life (truck mileage) $T_{p}$ ) specified in the regulations (including interstate GOST 30537-97) and specific truck performance $P_{T_{y}}$ as the main technical and operational parameter for mining haul trucks and taking into account their interrelationships (dependence (3)) the essential and sufficient nomenclature of the optimized parameters was compiled. It is stated in Fig. 3.

The problem of finding out how much each of these parameters influences the technical level generalized parameter chosen as the optimization criterion and subsequent generating an objective function model on this basis is a problem of approximation type and can be solved with the help of the theory of experiment design. Having been carried out, the correlation analysis of the interrelations between the parameters that are to be optimized determined the degree of their independence and allowed diminishing their number from 8 (Fig. 3) to $3\left(N_{e}^{r}, k_{T}\right.$ and $\left.T_{p}\right)$. 


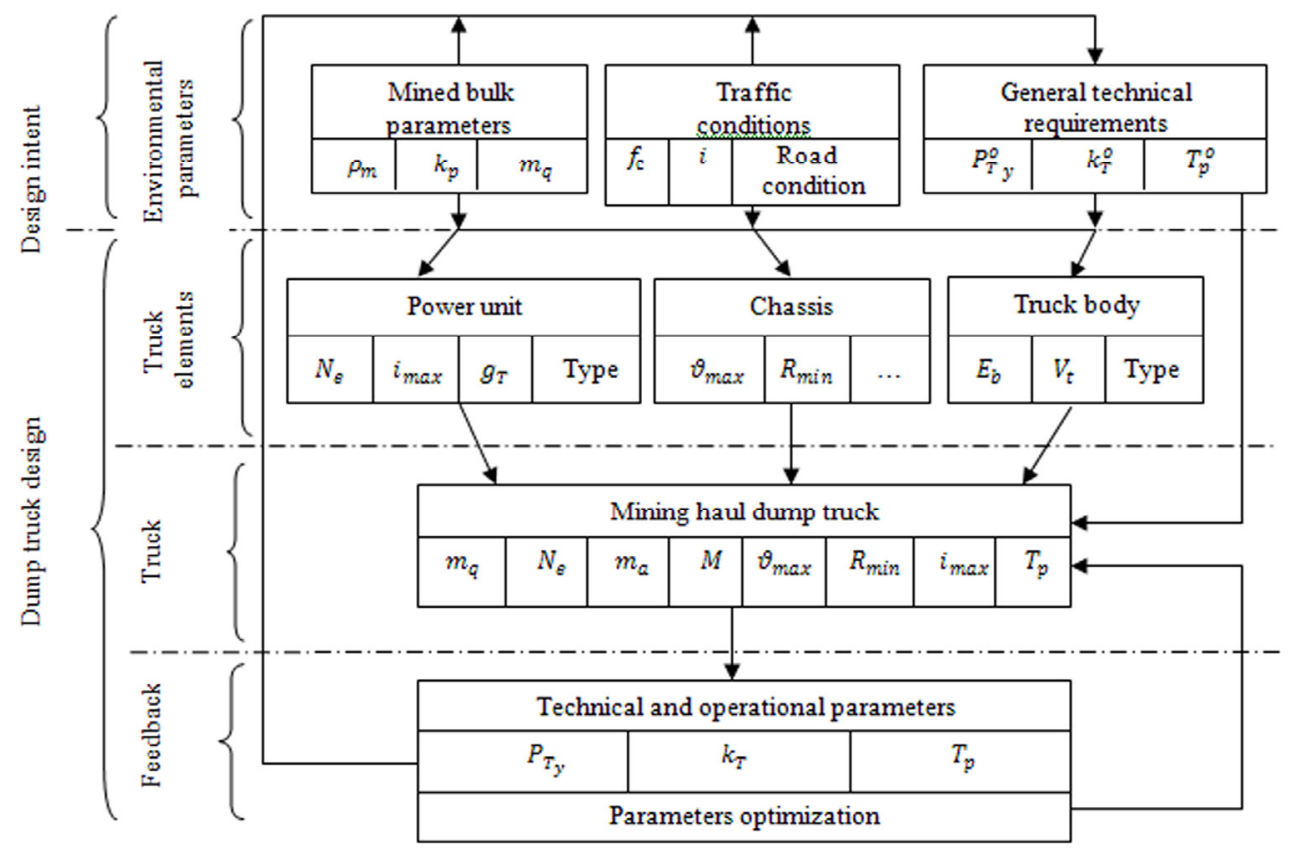

Fig. 2. Flow chart for haul truck design and truck parameters optimization $\left(\boldsymbol{\rho}_{\boldsymbol{m}}-\right.$ mined bulk density; $\boldsymbol{k}_{\boldsymbol{p}}$ - mined bulk loosening factor).

The evolved method is based upon the technical requirements regulated by GOST 30537 97 but it can be used for the purpose of optimization of haul truck parameters and other external conditions established by the customers. The method suggests a complete rethinking of the establishment of critical parameters for truck specifications.

The experiment confirmed linearity of the objective function models and all the constraints. The linearity is conditioned by the fact that all interrelations between the generalized and unique parameters of the technical level and between the truck parameters can be viewed as linearity with a reasonable degree of accuracy as suggested by regression parameters high values and correlation indices reliability.

\section{Conclusion}

The analysis of conditions and practices in mining machinery operation enabled to ascertain that the structure of "BelAZ" truck fleet is of relatively low quality. At present the number of guidance papers and materials for mining trucks adequate assessment and recommendations aimed at their technical level increase is not sufficient.

Integrated comparative assessment of the technical level of mining machinery produced by both domestic and foreign manufacturers highlighted the prospect of the technology advances in mining machinery and their implementation as early as the design stage. Increase in the technical level of newly developed mining automotive machinery can be achieved through the usage of theoretically grounded methods of optimal design which allow balancing all parameters.

Optimal design is based upon the optimization mathematical modeling of machinery operations and parameters. The objective function and constraints of the optimization mathematical model are viewed as a set of regression analysis equations which connect corresponding figures with the optimized parameters directly. It is suggested to use the 
technical level generalized parameters as an optimization criteria and its unique indicators as optimized parameters.

The implementation of scientific methodological and technical recommendations will allow bringing newly developed mining machinery up to the level that matches world standards.

\section{References}

1. S. Alarie, M. Gamache, Int. J. Surf. Min. Reclam. Env. 16, 59 (2002)

2. C.N. Burt, L. Caccetta, Int. J. Surf. Min. Reclam. Env. 21, 262 (2007)

3. C.N. Burt, L. Caccetta, Int. J. Surf. Min. Reclam. Env. 22, 84 (2008)

4. R.A. Carter, Eng. Min. J. 213, 28 (2012)

5. R.A. Carter, Eng. Min. J. 221, 30 (2010)

6. V.A. Temeng, F.O. Otunoye, J.O. Frendewey, Int. J. Surf. Min. Reclam. Env. 11, 203 (1997)

7. V.A. Temeng, F.O. Otunoye, J.O. Frendewey, Miner. Resour. Eng. 7, 59 (1998)

8. G. Lumley, Trends in performance of open cut mining equipment (GBI Mining Intelligence white paper, 2012)

9. C.H. Ta, J.V. Kresta, J.F. Forbes, H.J. Marquez, Int. J. Surf. Min. Reclam. Env. 19, 162 (2005)

A. Krause, C. Musingwini, J. S. Afr. I. Min. Metall. 107, 469 (2007)

10. S.V. Mkhatshwa, J. S. Afr. I. Min. Metall. 109, 223 (2009)

11. S. Tan, Production planning and operational control; new algorithms with application to the mining industry (PhD Thesis, Pennsylvania State University, USA, 1992)

12. Kolonja, N. Vasiljevic, Mine Planning and Equipment Selection (Balkema, Rotterdam, 2000)

13. J.W. White, J.P. Olson, S.I. Vohnout, CIM Bull. 86 (973), 43 (1993)

14. S.G. Ercelebi, A. Bascetin, J. S. Afr. I. Min. Metall. 109, 433 (2009)

B. Brown, Eng. Min. J. 213, 30 (2012)

15. Y. Kuo, Highway earthwork and pavement production rates for construction time estimation (PhD Thesis, University of Texas, USA, 2004) 
